Cardiopulmonary

Support and

Physiology

\title{
Thermo-wrap technology preserves normothermia better than routine thermal care in patients undergoing off-pump coronary artery bypass and is associated with lower immune response and lesser myocardial damage
}

Nahum Nesher, MD, ${ }^{a}$ Gideon Uretzky, MD, ${ }^{a}$ Steven Insler, MD, ${ }^{\mathrm{b}}$ Patrick Nataf, MD, ${ }^{\mathrm{c}}$ Inna Frolkis, MD, PhD, ${ }^{\mathrm{a}}$ Emmanuelle Pineau, MD, ${ }^{\mathrm{c}}$ Emmanuel Cantoni, MD, ${ }^{\mathrm{c}}$ Gil Bolotin, MD, ${ }^{\mathrm{a}}$ Moshe Vardi, MD, ${ }^{a}$ Dimitry Pevni, MD, Oren Lev-Ran, MD, ${ }^{a}$ Ram Sharony, MD, and Avi A. Weinbroum, MD ${ }^{d}$

Objective: Perioperative hypothermia might be detrimental to the patient undergoing off-pump coronary artery bypass surgery. We assessed the efficacy of the Allon thermoregulation system (MTRE Advanced Technologies Ltd, Or-Akiva, Israel) compared with that of routine thermal care in maintaining normothermia during and after off-pump coronary artery bypass surgery.

From the Department of Cardiothoracic Surgery $^{\mathrm{a}}$ and the Post-Anesthesia Care Unit, ${ }^{\mathrm{d}}$ Tel Aviv Sourasky Medical Center and the Sackler Faculty of Medicine, Tel Aviv University, Tel Aviv, Israel; the Cleveland Clinic Foundation, ${ }^{\mathrm{b}}$ Cleveland, Ohio; and the Centre Cardiologique du Nord, ${ }^{\mathrm{c}}$ Saint Dennis, Paris, France.

This study was supported by a grant from MTRE Advanced Technologies Ltd, OrAkiva Industrial Park, Israel.

Received for publication April 13, 2004; revisions received Aug 11, 2004; accepted for publication Aug 27, 2004.

Address for reprints: Avi A. Weinbroum, MD, Post-Anesthesia Care Unit, Tel Aviv Sourasky Medical Center, 6 Weizman St, Tel Aviv 64239, Israel (E-mail: draviw@ @asmc. health.gov.il).

J Thorac Cardiovasc Surg 2005; 129:1371-8 $0022-5223 / \$ 30.00$

Copyright $\odot 2005$ by The American Association for Thoracic Surgery

doi:10.1016/j.jtcvs.2004.08.021
Methods: Patients undergoing off-pump coronary artery bypass surgery were perioperatively and randomly warmed with the 2 techniques $(n=45$ per group). Core temperature, hemodynamics, and troponin I, interleukin 6 , interleukin 8 , and interleukin 10 blood levels were assessed.

Results: The mean temperature of the patients in the Allon thermoregulation system group (AT group) was significantly $(P<.005)$ higher than that of the patients receiving routine thermal care (the RTC group); less than $40 \%$ of the latter reached $36^{\circ} \mathrm{C}$ compared with $100 \%$ of the former. The cardiac index was higher and the systemic vascular resistance was lower $(P<.05)$ by $16 \%$ and $25 \%$, respectively, in the individuals in the AT group compared with in the individuals in the RTC group during the 4 postoperative hours. End-of-surgery interleukin 6 levels and 24-hour postoperative troponin I levels were significantly $(P<.01)$ lower in the patients in the AT group than in the RTC group. The RTC group's troponin levels closely correlated with their interleukin 6 levels at the end of the operation $(R=0.51, P=$ $.002)$.

Conclusions: Unlike routine thermal care, the Allon thermoregulation system maintains core normothermia in more than $80 \%$ of patients undergoing off-pump coronary artery bypass surgery. Normothermia is associated with better cardiac and vascular conditions, a lower cardiac injury rate, and a lower inflammatory response. The close correlation between the increased interleukin 6 and troponin I levels in the routine thermal care group indicates a potential deleterious effect of lowered temperature on the patient's outcome. 
$\mathrm{M}$ ild perioperative hypothermia $\left(1^{\circ} \mathrm{C}-2^{\circ} \mathrm{C}\right.$ less than the normal core body temperature) is common in almost any major operation, occurring in 50\% to $75 \%$ of the patients. ${ }^{1}$ It results from anesthesia-induced impairment of thermoregulation, ${ }^{2}$ exposure to a cold ambient, and altered distribution of body heat. ${ }^{3}$ Several investigators demonstrated that perioperative hypothermia alters the immune system function and therefore increases the body's susceptibility to comorbidity. ${ }^{4,5}$

Warming of patients undergoing surgical intervention is mostly achieved by conventional means, such as routine thermal care (RTC), consisting of drapes, the infusion of warm $\left(38^{\circ} \mathrm{C}\right)$ fluids, or the ejecting of warm $\left(38^{\circ} \mathrm{C}\right)$ air over the body. The minimizing of evaporation from the airways by introducing the Bact Hme Port (Pharma Systems AB, Knivsta, Sweden) between the endotracheal tube and the ventilator itself might also be used for such purposes. The Allon thermoregulation system (AT; MTRE Advanced Technologies Ltd, OrAkiva, Israel) represents an advanced technology of patient warming that has been recently applied in the operating room (OR) and described by us in detail previously. ${ }^{6}$

The use of cardiopulmonary bypass (CPB) is associated with a systemic inflammatory response because of its exposure to a large foreign-body surface area. ${ }^{7,8}$ Systemic immune response syndrome and reperfusion injury of the heart reflect the possible clinical effect of this massive activation of the immune system. Inflammatory cytokines, such as interleukin (IL) 6 , IL-8, and the anti-inflammatory cytokine IL-10 are thus activated and released during the operation. ${ }^{7,8}$ Independently of $\mathrm{CPB}$, there is also a general activation of the immune system during any surgical procedure, representing a physiologic response to surgical stress and trauma. ${ }^{5}$

Until recently, the level of response of the immune response system associated with cardiac surgery was attributed predominantly to the use of $\mathrm{CPB},{ }^{9}$ but comparative data on the effects of $\mathrm{CPB}$ on this system to the response evoked by surgical trauma per se are scant. Notably, the immune response to surgical stress, trauma, or both, might be exacerbated by body hypothermia. ${ }^{10}$

The aims of the current study were (1) to evaluate the efficacy of the AT system versus the RTC methods in main-
TABLE 1. Demographic and medical characteristics and surgical data ( $n=45$ per group)

\begin{tabular}{lcc}
\hline Parameter & AT group & RTC group \\
\hline Age $(\mathrm{y})$ & $69.2 \pm 17.1$ & $68.2 \pm 12.6$ \\
Male sex $(\mathrm{n})$ & $32(70)$ & $24(52)$ \\
Weight $(\mathrm{kg})$ & $73.5 \pm 7.4$ & $68.2 \pm 15.0$ \\
Height $(\mathrm{cm})$ & $167.5 \pm 8.6$ & $164.6 \pm 9.9$ \\
Body surface area $\left(\mathrm{m}^{2}\right)$ & $1.87 \pm 5.2$ & $1.82 \pm 0.7$ \\
Body mass index $\left(\mathrm{kg} / \mathrm{m}^{2}\right)$ & $26.9 \pm 2.6$ & $24.9 \pm 5.6$ \\
Hypercholesterolemia $(\mathrm{n})$ & $32(70)$ & $22(48)$ \\
Hypertension $(\mathrm{n})$ & $34(75)$ & $18(40)$ \\
Diabetes $(\mathrm{n})$ & $21(49)$ & $26(52)$ \\
Serum creatinine 1.5-2 mg/dL & $2(4)$ & $3(6)$ \\
Peripheral vascular disease $(\mathrm{n})$ & $7(15)$ & $5(12)$ \\
Previous CVA (n) & $3(7)$ & $2(4.5)$ \\
Past history of smoking $(\mathrm{n})$ & $22(48)$ & $26(52)$ \\
EuroSCORE & $2.9(0.9-8.2)$ & $3.2(2.0-9.9)$ \\
Duration of the operation $(\mathrm{min})$ & $218.0 \pm 96.2$ & $228.2 \pm 62.8$ \\
Bypass grafts $(\mathrm{n})$ & $2.1 \pm 0.5$ & $2.2 \pm 0.6$
\end{tabular}

Values are presented as means $\pm S D$, median (range), or absolute value (percentage) where shown. There were no statistically significant differences between the groups for all reported data. $A T$, Allon thermoregulation system; $R T C$, routine thermal care; CVA, cerebrovascular accident.

taining normothermia in patients undergoing off-pump coronary artery bypass surgery (OPCAB) and (2) to measure the effect of each technique with other characteristics observed during $\mathrm{OPCAB}$, such as hemodynamic and myocardial changes and variations of the immune response system.

\section{Patients and Methods}

This randomized, prospective, open-labeled, multicenter investigation involved patients of the Tel-Aviv Sourasky Medical Center, Tel Aviv, Israel; the Cleveland Clinic Foundation, Cleveland, Ohio; and the Centre Cardiologie du Nord, Paris, France.

\section{Patient Enrollment}

The study was approved by the ethics committees of the participating centers, and each patient signed an approved informed consent form. Entrance criteria were a patient's first-time referral for isolated coronary bypass surgery and a technically feasible $\mathrm{OPCAB}$ in that patient. Patients were excluded in cases of emer-

TABLE 2. Perioperative hemodynamic and protein profiles ( $n=45$ per group)

\begin{tabular}{|c|c|c|c|c|}
\hline \multirow[b]{2}{*}{ Parameter } & \multicolumn{2}{|c|}{ Anesthesia, induction } & \multicolumn{2}{|c|}{30 min into the operation } \\
\hline & AT & RTC & AT & RTC \\
\hline $\mathrm{MABP}(\mathrm{mm} \mathrm{Hg})$ & $91.4 \pm 12.3$ & $89.5 \pm 16.3$ & $82.5 \pm 13.4$ & $85.6 \pm 15.3$ \\
\hline HR (beats/min) & $88.6 \pm 8.0$ & $85.0 \pm 15.0$ & $87.0 \pm 11.0$ & $84.6 \pm 9.0$ \\
\hline CK-MB mass $(\mu \mathrm{g} / \mathrm{L})$ & $1.2 \pm 6.3$ & $3.1 \pm 3.6$ & $2.1 \pm 2.8$ & $3.4 \pm 7.6$ \\
\hline Troponin I (ng/mL) & $0.4 \pm 1.6$ & $0 \pm 0$ & $0.4 \pm 1.4$ & $0 \pm 0$ \\
\hline
\end{tabular}


gency or concomitant valvular surgery, Q-wave myocardial infarction during the previous 3 weeks, poor left ventricular function (ie, ejection fraction $<30 \%$ ), body mass index of greater than 35 $\mathrm{kg} / \mathrm{m}^{2}$, extensive dermopathy (including past skin burns), and chronic renal failure requiring dialysis. Also excluded were patients with clotting abnormalities (eg, prothrombin time, >60 seconds; partial thromboplastin time, more than twice the normal range), platelets of less than $70,000 / \mathrm{mm}^{3}$, white blood cells of less than 3000/greater than 14,000, uncontrolled diabetes (fasting glucose level $>250 \mathrm{~g} / \mathrm{dL}$ ), evidence of sepsis or of any type of infection within a week before screening, or evidence of endocrinopathy or the use of endocrine replacement substances. There was no age restriction.

\section{Group Assignment}

Patients who met the OPCAB criteria (see below) were randomized by a computer-generated random-number table to the AT or RTC group on the day of the operation. The study design was not blinded intraoperatively because of the application of the different warming devices, but it was blinded to the surgeons who assigned the patients to OPCAB versus $\mathrm{CPB}$, as well as to the postoperative ward nursing staff. Demographic and clinical preoperative characteristics were later used to calculate the EuroSCORE (European System for Cardiac Operation Risk Evaluation, ranging between 1 and 15) for each participant.

\section{Patient Selection for OPCAB and Later Exclusion Criteria}

Potential study patients also needed to meet the criteria for undergoing an OPCAB procedure. Each center was staffed by an independent surgeon experienced in OPCAB who decided who would be suitable for such a procedure on the basis of routine institutional policy (eg, which vessel needed revascularization) and who was considered a suitable candidate for CPB (eg, existence of very small coronary vessels). Intraoperative conversion to CPB could be carried out if hemodynamic stability could not be achieved despite aggressive efforts (ie, fluid or catecholamine administration) or if the coronary vessels turned out to be unsuitable for OPCAB (eg, small and atheromatous, calcified, or deeply intramyocardial). Patients were excluded from the study if the temperature in the $\mathrm{OR}$ was less than $17^{\circ} \mathrm{C}$ or greater than $19^{\circ} \mathrm{C}$ during the time of the operation. The above patients were subsequently replaced by others.

Other exclusions (not replaced) were patients who bled postoperatively and required reoperation within 4 hours after the operation, those who underwent perioperative myocardial infarction (MI) diagnosed on the basis of an immediate postoperative hemodynamic instability and later supported by a new Q-wave on the electrocardiogram, or those whose serum total creatine kinase (CK) levels increased more than 5-fold greater than the upper limit associated with an MB fraction of greater than $6 \%$. Finally, patients who experienced a late postoperative MI confirmed on the basis of positive coronary angiography were dropped from the study.

The data of patients who bled after the first 4 postoperative hours and underwent reoperation were not replaced by the data of other patients. Their demographic and intraoperative data were included in the cohort information (by using the intent-to-analyze test), with the distinction that the bleeding and blood replacement data of these patients was not included in the cohort data.

\section{Patient-Warming Modalities}

The OR temperature was kept between $17^{\circ} \mathrm{C}$ and $19^{\circ} \mathrm{C}$. Warming of the patients in each group was initiated before the induction of anesthesia and was continued throughout the operation and for the following 2 hours in the intensive cardiac care unit (ICCU). The Allon system that was used in the AT study group consists of 3 elements: a microprocessor-controlled heating-cooling unit, body temperature sensors (ie, core [rectal] and skin thermistors), and a specially designed garment that wraps around the patient. ${ }^{6}$ Continuous monitoring of the patient's rectal and skin temperature is performed with the thermistors. All skin temperature measurements are recorded with 2 skin sensors. A feedback-controlled microprocessor unit receives the data from the rectal thermistor, which serves as the afferent arm. Water is then circulated by a pump and is controlled and maintained at a set point ranging from $18^{\circ} \mathrm{C}$ to $39.5^{\circ} \mathrm{C}$ in a closed loop between the garment and the unit. Water temperature is continuously adjusted through the feedback loop to reach a predetermined temperature.

The garment is composed of a 2-layer plastic biocompatible material approved by the US Food and Drug Administration. The outer layer is made of nonwoven polypropylene material, and the inner layer is made of polyethylene. The specially designed garment wraps around the patient's body over the entire area of the back, the sides of the body to the midclavicular line, and the shoulders and legs in a way that it does not interfere with the surgical field. Water flows between the 2 layers, transferring controlled heat throughout the operation. This water is the actual heat exchanger, being the garment the only component in direct contact with the patient's skin surface. All of the garment's com-

\begin{tabular}{|c|c|c|c|c|c|}
\hline \multicolumn{2}{|c|}{ End of anastomoses } & \multicolumn{2}{|c|}{ End of the operation } & \multicolumn{2}{|c|}{4 h postoperatively } \\
\hline AT & RTC & AT & RTC & AT & RTC \\
\hline $90.1 \pm 14.3$ & $92.4 \pm 9.6$ & $88.6 \pm 16.5$ & $85.5 \pm 13.2$ & $87.3 \pm 19.2$ & $84.6 \pm 14.7$ \\
\hline $86.0 \pm 17.0$ & $78.0 \pm 12.0$ & $91.0 \pm 9.0$ & $88.0 \pm 12.0$ & $103.0 \pm 12.0$ & $95.0 \pm 12.0$ \\
\hline $2.4 \pm 3.6$ & $8.0 \pm 18.9$ & $4.2 \pm 4.7$ & $11.1 \pm 19.9^{*}$ & $17.8 \pm 26.6$ & $23.2 \pm 40.1$ \\
\hline $1.4 \pm 3.4$ & $1.9 \pm 2.3$ & $4.7 \pm 6.4$ & $13.8 \pm 3.7 \dagger$ & $8.1 \pm 21.4$ & $19.4 \pm 3.7^{*}$ \\
\hline
\end{tabular}

Values are presented as means \pm SD. There were no statistically significant differences between the groups for all reported data throughout the study period (by ANOVA with repeated measures). $A T$, Allon thermoregulation system; $R T C$, routine thermal care; $M A B P$, mean arterial blood pressure; $H R$, heart rate; $C K-M B$, creatine kinase myocardial fraction. $* P<.05, \dagger P<.01$ (by $t$ test) versus the AT group. 


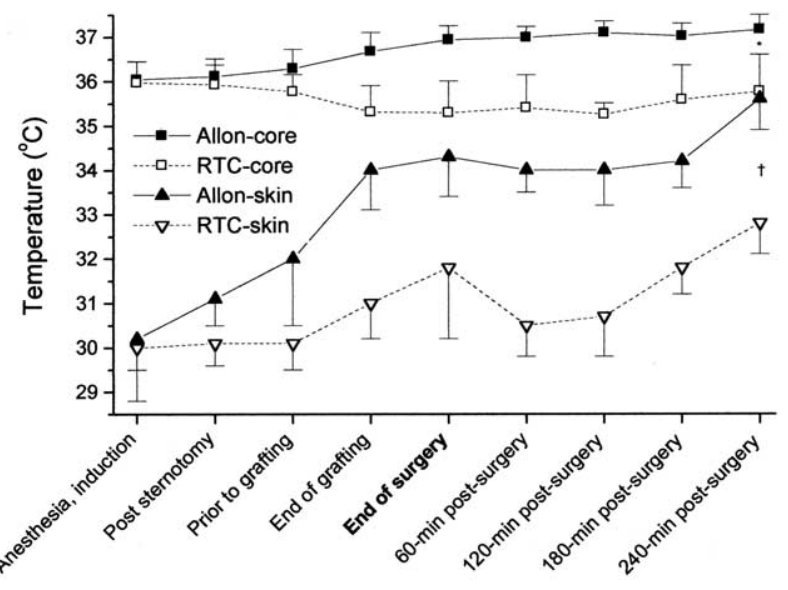

Figure 1. Core (upper graph) and skin (lower graph) temperatures. Temperatures were constant or augmented in the Allon Thermoregulation system group but decreased over most of the surgical period in the RTC group. ${ }^{*} P<.001 ;+P<.003$ (by ANOVA) between the groups.

ponents are made of disposable materials. It is puncture resistant and reusable and can be sterilized.

All patients in the RTC group were warmed with a combination of water blankets (Thermostat T1000; JMW Medical Systems Ltd, Midlothian, United Kingdom) and intravenous fluid warmers (Fenwal model BW5, Deerfield, Ill) from the time of induction of anesthesia throughout the entire perioperative period and an air warmer $\left(38^{\circ} \mathrm{C}\right.$; Thermacare; Gaymar Industries Inc, Orchard Park, $\mathrm{NY}$ ). After the termination of the operation, these patients were covered with convective air warmers (Bair Hugger cardiac blanket; Augustine Medical Inc, Eden Prairie, Minn) and warm blankets until the end of the postoperative phase of the analysis.

\section{Anesthesia Protocol}

Induction of standard anesthesia consisted of $2 \mathrm{mg}$ of midazolam, $1 \mathrm{mg} / \mathrm{kg}$ propofol, medium-dose fentanyl $(5-15 \mu \mathrm{g} / \mathrm{kg}$ ), and pancuronium $(1.5 \mathrm{mg} / \mathrm{kg})$, followed by endotracheal intubation. Anesthesia was maintained by infusions of the 2 latter drugs, and dose changes were carried out to keep the patient adequately anesthetized and hemodynamically stable. All patients were ventilated by using oxygen with volume-preset time-cycled ventilators ( $10 \mathrm{~mL} / \mathrm{kg}$ tidal volume); isoflurane ( $0.4 \%-0.8 \%$ inspired concentration) was used as deemed necessary to the attending anesthetist. Catecholamines and nitrites were given by the attending anesthetist up to 24 hours postoperatively, as deemed necessary.

\section{Surgical Procedures}

OPCAB was performed through a midline sternotomy, followed by partial heparinization, with the left internal thoracic artery and (occasionally) the right internal thoracic artery, the radial artery, and/or the saphenous veins as conduits.

Mechanical stability of the coronary arteriotomy areas was achieved with the Octopus II (Medtronic Inc, Minneapolis, Minn).
No shunts were used. Proximal anastomoses on the aorta were done after the distal anastomoses were carried out with a partial clamp. Reversal of heparinization was implemented only when there was evidence of a bleeding tendency: doses of protamine sulfate ( $50 \mathrm{mg}$ per dose) were added if the activated clotting time was greater than $50 \%$ of the patient's baseline measurement, if clots were not detected within the operating field, or both. Nitroglycerin and dopamine were administered ad hoc, as deemed necessary by the surgeon.

\section{Assessment of Vital Signs}

Perioperative monitoring of vital signs followed standard institutional protocols. These consisted of 2-surface electrocardiographic leads, an intraradial arterial line, pulse oximetry, end-tidal $\mathrm{CO}_{2}$, and a Swan-Ganz pulmonary artery catheter (Baxter Vigilance Monitor Model VGS; Baxter Healthcare Corp, Irvine, Calif). These devices enabled direct assessment of heart rate, invasive blood pressures, pulmonary artery and wedge pressures, cardiac output and cardiac index $\left(\mathrm{CI}\right.$; in $\left.\mathrm{L} \cdot \mathrm{min}^{-1} \cdot \mathrm{m}^{-2}\right)$, and systemic vascular resistance $\left(\mathrm{SVR}\right.$; in dynes $\left.\cdot \mathrm{s}^{-1} \cdot \mathrm{cm}^{-5}\right)$. Urinary bladder and skin temperatures were also continuously measured.

\section{Blood Loss and Replacement}

On completion of the operation, the patients were transferred to the ICCU, where they were allowed to wake up when they became hemodynamically stable and when blood loss from the chest drain reached less than $100 \mathrm{~mL} / \mathrm{h}$. They were given packed red blood cells only if the hemoglobin concentration was less than $8 \mathrm{mg} / \mathrm{dL}$ or if patients showed hemodynamic instability when the hemoglobin concentration was 8 to $10 \mathrm{~g} / \mathrm{dL}$. Patients with apparent volume depletion received crystalloid solutions.

Re-exploration was performed if blood was drained at a rate more than $400 \mathrm{~mL}$ during the first postoperative hour or greater than $200 \mathrm{~mL} / \mathrm{h}$ for more than 4 hours postoperatively. The chest tube was withdrawn within 24 hours after the operation or when the amount of drained blood was less than $200 \mathrm{~mL} / \mathrm{d}$. Patients were discharged from the ICCU to the ward when they were fully awake, hemodynamically stable, and had minimal chest tube drainage.

\section{Cardiac Protein and Cytokine Measurements}

Perioperative ischemic myocardial injury was assessed by determining serum levels of total CK-MB mass fraction and troponin I. Immunologic changes were assessed by measuring IL-6, IL-8, and IL-10 levels in the serum.

Blood samples were collected at the time of induction of anesthesia, after sternotomy, at the completion of the anastomoses, at the end of the operation, and 6 and 24 hours later. For cytokine measurements, blood samples were collected twice, once at the time of induction of anesthesia and again at the end of the operation. Serum separation was performed immediately after blood removal, and samples were kept at $-70^{\circ} \mathrm{C}$ until analyzed. Serum troponin I (physiologic range, $<0.5 \mathrm{ng} / \mathrm{mL}$ ) and CK-MB mass (physiologic range, $<30$ IU/L) levels were determined by using an immunoassay method (microparticle enzyme immunochemical assay; Abbott Axsym System, Abbott, Italy). The cytokines were assessed by using an enzyme-linked immunoabsorbent assay with human IL-6, IL-8, and IL-10 ultrasensitive kits (Bio Source Int, 


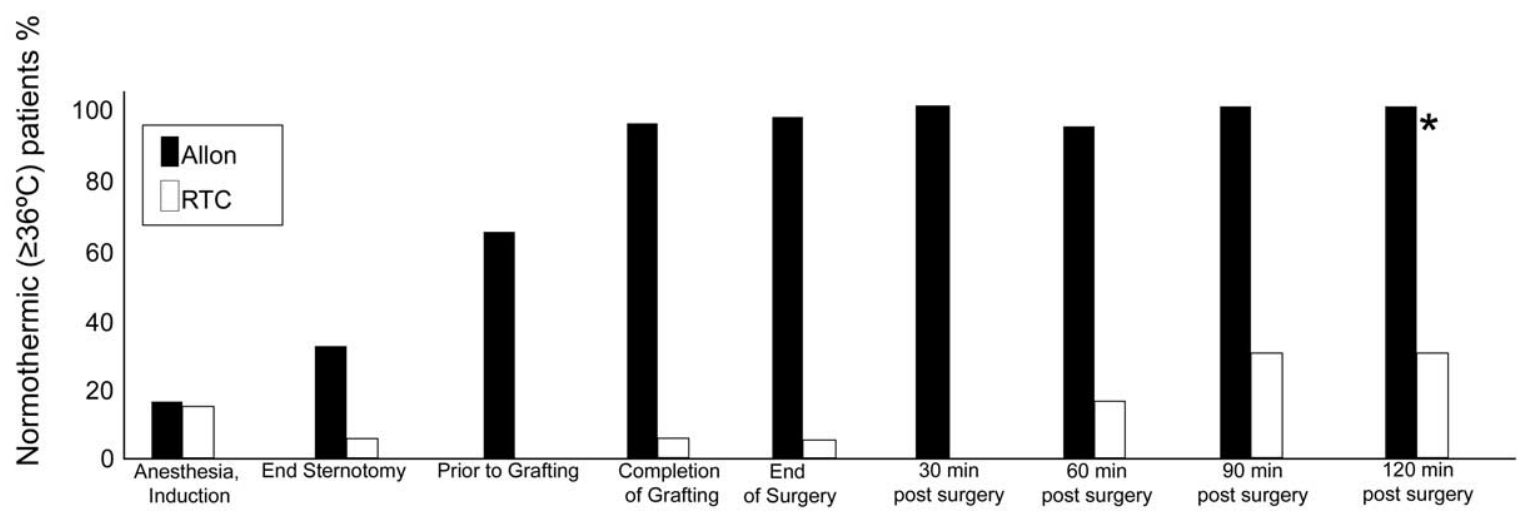

Figure 2. Temperature distribution. The percentage of patients in each study group whose core temperature reached $36^{\circ} \mathrm{C}$ or more is shown. ${ }^{*} P<.001$ (by ANOVA) between the groups.

Camarillo, Calif). All factors were analyzed in the Karolinska Hospital Clinical Chemistry Department, Stockholm, Sweden.

\section{Statistical Analysis}

The sample size (45 patients per group) was the result of a power table calculation on the basis of a $5 \%$ difference between the groups $(\alpha=.05)$, an average of a $2^{\circ} \mathrm{C}$ difference between group temperatures $(\Delta=2)$, and an $80 \%$ power to detect a $5 \%$ difference $\left(1.8^{\circ} \mathrm{C}\right)$ of the $36.0^{\circ} \mathrm{C}$ optimal temperature. Demographic and background values of the patients (ie, age, weight, anesthetic, and baseline temperature and vital signs) were compared with 1-way analyses of variance (ANOVAs). The data of all patients who were dropped from the cohort after the operation had started were evaluated by the intent-to-treat test. ANOVA with repeated measures was used to determine changes in temperature trends, vital signs, and troponin I levels throughout the study period. The mean values of the intraoperative and postoperative temperatures at the determined time points and the total number of grafts were compared by the paired $t$ test. The same test was used to analyze differences in mean vital signs and troponin I protein levels between the 2 groups. The nonparametric Mann-Whitney rank test was used to determine differences in IL-6, IL-8, and IL-10 levels, as well as in EuroSCOREs. The Spearman correlation coefficient was applied to determine the grade of correlation between various ILs and troponin I within each group. The $\chi^{2}$ and Fisher exact tests were used to analyze categoric data (eg, type of grafts). All ANOVA tests were followed by the post-hoc Tukey test. All values are presented as means $\pm \mathrm{SD}$.

\section{Results}

Of the 90 patients who were prospectively and randomly enrolled in the study, 5 were excluded postoperatively. One patient in each group underwent reoperation within less than 4 postoperative hours as a result of postoperative bleeding. One patient in each group was also excluded because of undergoing operations during an undiagnosed acute MI: they both demonstrated high levels of cardiac enzymes throughout the study period. The fifth patient was excluded

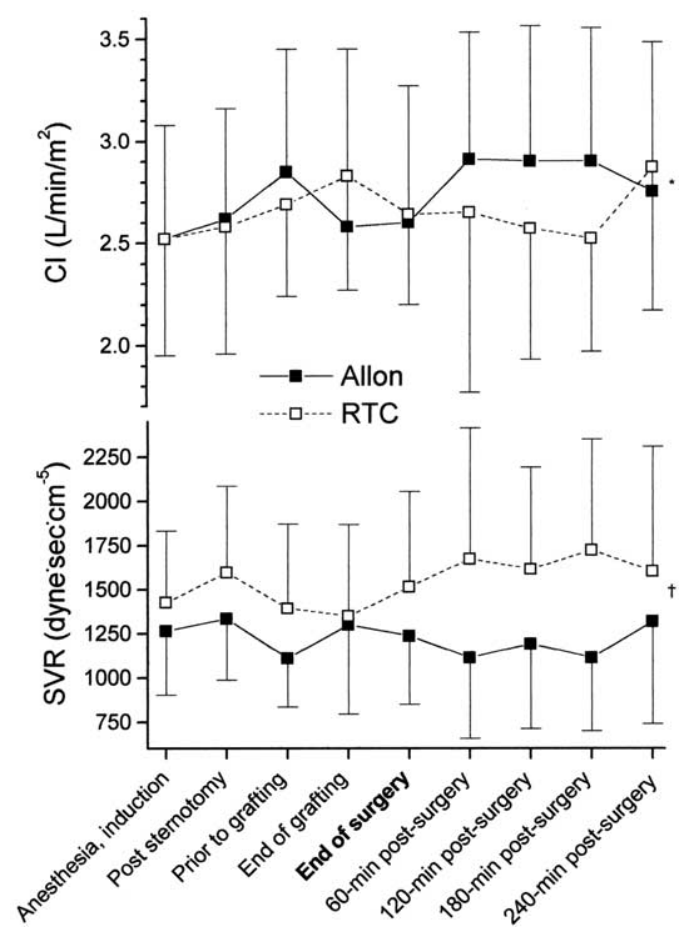

Figure 3. SVR (lower plain) and CI (upper plain). SVR increased and $\mathrm{Cl}$ decreased in the RTC group but remained stable in the Allon Thermoregulation system group. ${ }^{*} P<.001 ;+P<.01$ (by ANOVA) between the groups.

from the RTC group because of a perioperative MI induced by means of acute occlusion of an anastomosis that was later visualized angiographically.

Two patients in the RTC group and 3 patients in the AT group underwent reoperation for postoperative bleeding more than 4 hours after the operation; their background and 
TABLE 3. Postoperative complication rate

\begin{tabular}{lcc}
\hline Parameter & $\begin{array}{c}\text { AT group } \\
(\mathbf{n}=\mathbf{4 3})\end{array}$ & $\begin{array}{c}\text { RTC group } \\
\text { (n = 42) }\end{array}$ \\
\hline Mortality $(<30 \mathrm{~d})^{*}$ & 1 & 0 \\
Atrial fibrillation & $15(33)$ & $17(35)$ \\
Cerebrovascular attack $\dagger$ & 0 & 1 \\
New-onset renal failure & & \\
$\quad$ By creatine clearance test & 2 & 3 \\
$\quad$ Requiring dialysis & 0 & 1 \\
Pleural effusion or pneumothorax & 3 & 2 \\
Infection requiring antibiotic therapy & 5 & 4 \\
\hline
\end{tabular}

Data are presented as the number of patients (percentage). There were no statistically significant differences between the groups for the reported data. AT, Allon thermoregulation system; RTC, routine thermal care. *Caused by cardiac arrest. $\dagger$ Transient or permanent.

demographic data were therefore included in the cohort presentation but not in the assessments of specific blood loss and replacement. Finally, 7 patients were converted from $\mathrm{OPCAB}$ to $\mathrm{CPB}$ during the operation, and they were replaced by 7 other patients undergoing OPCAB.

The demographic and the preoperative clinical data of the participants revealed no significant differences between the 2 groups (Table 1 and data not shown, respectively). The calculated EuroSCOREs were also similar between the groups (Table 1).

\section{Perioperative Data}

Respiratory data and the amounts of the anesthetic agents used during the operation were similar in both groups (data not shown). The total number of grafts was also similar between the groups (Table 1), as were the graft types (skeletonized left or right internal thoracic artery, radial artery, or saphenous vein; data not shown). The total OR time was also similar (Table 1), as was the differential postischemia OR time (AT group, $46 \pm 10$ minutes; RTC group, $51 \pm 9$ minutes; $P=.08$ ).

Table 2 displays the perioperative trends in the patients' blood pressures and heart rates: they did not change perioperatively. The 24-hour values were not different between the groups (data not shown). Both the core and skin temperatures (Figure 1) were constantly higher in the AT group compared with those in the RTC group $(P=.05$ after sternotomy and $P=.001$ at the end of the operation, $t$ test). Overall, skin temperature in patients receiving AT recuperated slowly but constantly; it did not in the individuals receiving RTC. Figure 2 shows the percentage of patients in each group who attained normothermia $\left(\geq 36.0^{\circ} \mathrm{C}\right)$ : less than $40 \%$ of the patients in the RTC group versus $100 \%$ of the patients in the AT group $(P<.001)$.

The SVR values were not different between the groups during the operation. They were, however, significantly lower $(P<.01$, ANOVA, group effect) starting at the end of the operation $(P=.001, t$ test $)$ and for 2 postoperative hours in the AT group compared with in the RTC group (Figure 3, lower plane). After this period, the SVR values of the 2 groups became similar again. The mean CI was also significantly $(P=.05$, ANOVA, group effect) higher in the AT group than in the RTC group starting at the end of the operation and lasting to the end of the study period (Figure 3 , upper plane).

Hourly chest tube output was similar between the 2 groups (data not shown). The number of blood cell units required in the AT group was similar to that in the RTC group (AT group, $1.3 \pm 3.5$; RTC group, $2.2 \pm 1.5 ; P=.1$ ). Crystalloids were administered to a similar extent (data not shown). The total amounts of dopamine and nitroglycerin administered to the patients were similar for the 2 groups both intraoperatively $(26.6 \pm 18.7[\mathrm{AT}]$ and $27.7 \pm 12.6$ $\mathrm{mg}$ [RTC], $P=1.0 ; 12.6 \pm 17.8$ [AT], $16.7 \pm 11.9 \mathrm{mg}$ [RTC], $P=.9$, respectively) and postoperatively (126.8 \pm 73.3 [AT], $133.5 \pm 89.9 \mathrm{mg}$ [RTC], $P=1.0 ; 49.6 \pm 51.8$ [AT], $56.6 \pm 72.9 \mathrm{mg}$ [RTC], $P=.90$, respectively).

Time to extubation of the patients was significantly shorter in the AT group ( $7.0 \pm 3.4$ hours postoperatively) than in the RTC group (11.4 \pm 7.1 hours, $P=.01)$. The length of hospital stay was not statistically different between the groups $(5.6 \pm 4.0$ days [AT], $7.2 \pm 11.2$ days [RTC], respectively; $P=.28$ ) nor was the time to discharge. The rates of postoperative complications were similar between the groups (Table 3).

\section{Cardiac Protein and Cytokine Profiles}

The overall serum CK-MB mass fraction and troponin I levels were comparable between the 2 study groups at the time of anesthesia induction and throughout the operation. The CK-MB values increased sharply immediately after the end of the operation in both groups and remained similarly increased throughout the study (Table 2) and up to 24 hours postoperatively (data not shown). In contrast, the troponin values increased at the end of the operation, especially in the RTC group, and remained unaltered for 4 hours (Table 2), as well as for 24 hours (data not shown).

The profiles of the tested cytokines are illustrated in Figure 4. Serum IL-6, IL-8, and IL-10 levels were significantly higher at the end of the operation in both the RTC and AT groups compared with their own values at the time of the induction of anesthesia (baseline); only the IL-6 values, however, were significantly lower in the AT group compared with those in the RTC group (Figure 4).

There was a direct correlation between the individual's duration of surgical intervention and the troponin I $(R=$ $0.64, P=.002)$, IL-6 $(R=0.84, P=.0001)$, IL-8 $(R=$ $0.68, P=.0001)$, and IL-10 $(R=0.6, P=.001)$ levels. Also, the IL-6 plasma levels directly correlated with the troponin values at the end of the operation in both groups $(R$ 


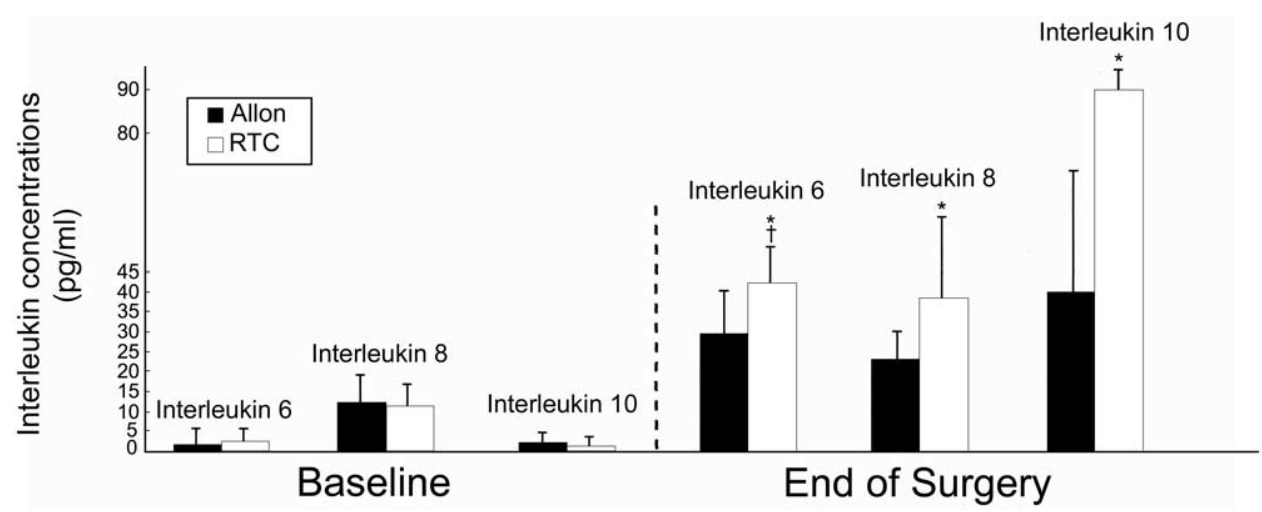

Figure 4. Preoperative and postoperative IL levels. All IL levels increased by the end of the operation in both groups. ${ }^{*} P=.0001$ (by $t$ test) versus the corresponding baseline values; $† P=.008$ versus the RTC group.

$=0.51, P=.004)$ but not with the IL-8 or IL-10 values $(R$ $=0.33, P=.07 ; R=0.35, P=.08$, respectively).

\section{Discussion}

Our current results show that stable normothermic conditions were maintained and even enhanced in the AT group during the entire OPCAB study period compared with the failure to reach the target value of $36^{\circ} \mathrm{C}$ in the RTC group. Both groups had a systemic flare-up of the postoperative immune response, as expressed by an increase of proinflammatory cytokines (IL-6 and IL-8) and of the anti-inflammatory cytokine IL-10. A better controlled immune response (lower values of IL-6), superior hemodynamic conditions (increased CI and decreased SVR), and minimal myocardial injury were achieved in the normothermic AT group compared with in the hypothermic RTC group.

Although it is rarely desired, and in spite of inexpensive and safe methods of warming, mild perioperative hypothermia (approximately $2^{\circ} \mathrm{C}$ less than the normal core body temperature) is a common occurrence in most major surgical procedures, accounting for $50 \%$ to $75 \%$ of all surgical patients. ${ }^{1}$ It results from anesthetic-induced impaired thermoregulation, ${ }^{2}$ exposure to a cold ambient, and altered distribution of body heat. ${ }^{3}$ These factors were similar between the 2 groups in the current study.

It is currently held that mild-to-moderate hypothermia during cardiac surgery plays a protective role in preventing myocardial damage by reducing oxygen consumption, mainly in the heart. ${ }^{11}$ Our data might contradict this conviction and suggest that the protective role of hypothermia might not bestow any benefit in patients undergoing OP$\mathrm{CAB}$. Indeed, there is no need to reduce a patient's core temperature during OPCAB surgery, even to the mild level of hypothermia that was thought to be desirable when CPB is conducted. ${ }^{1}$ AT was also associated with reduced levels of IL-6 and troponin and with improved hemodynamics, findings that suggest that normothermia is closely related to reduced inflammatory responses to stress and subsequently to a lower rate of myocardial damage. This latter finding was unexpected and one that we believe has not been reported before.

Until recently, the systemic immune response associated with cardiac surgery was attributed predominantly to the use of CPB. ${ }^{7,8,12}$ A clear correlation was also shown to exist between the duration of the operation and crossclamp time and IL levels, ${ }^{13,14}$ and the activation of the immune system is a physiologic response to stress and trauma. ${ }^{15}$ Our data support the abovementioned conclusion that most of the observed immune response was attributable to the surgical trauma per se rather than to CPB. Nevertheless, because the IL-6 level was lower in our AT group, we further suggest that patient body temperature played a role in modulating the inflammatory response as well.

The increased troponin I and cytokine levels that were recorded in the RTC group and the unexpected direct correlation between IL-6 and troponin levels deserve a separate mention. We suggest that the hypothermic group sustained more extensive myocardial damage that correlated directly with IL-6. We chose to assess troponin, a specific marker of myocardial injury, because it had been previously used to detect perioperative myocardial damage after CABG surgery. ${ }^{6,16}$ Because this correlation was minimal in the AT group, our results indicate that proinflammatory cytokines appear to exert an additive damaging effect on the myocardium in the presence of hypothermic conditions.

IL-6 was found to be released from vascular smooth muscle cells and to stimulate the induction of endogenous platelet-activated growth factor, which causes a significant increase of intracellular calcium levels and subsequent vasoconstriction. ${ }^{17}$ Recent studies have also shown that the release of IL-6 from vascular smooth muscle cells might be triggered or induced by potent vasoconstrictors, such as 
angiotensin II, ${ }^{18}$ endothelin, ${ }^{19}$ serotonin, ${ }^{20}$ and norepinephrine. ${ }^{21}$ Increased serum IL-6 levels might thus reflect an increase in the adrenergic drive and therefore might be related to SVR changes, but we could not explore this aspect or the relevance of increased IL-6 levels to postoperative complications because vasoactive drugs were used similarly in both of our study groups.

There are several limitations to this study. Although the results are meaningful statistically, a larger cohort would probably better reflect the differences between the conventional and the new warming technologies. A second limitation is that ours were relatively low-risk patients, and highrisk subjects might have better differentiated between the parameters we examined. Because this study was undertaken in 3 different centers, it represents their combined complication rates, although the immediate outcome after OPCAB surgery varied very little from the rate of complications reported by others. ${ }^{22,23}$ In addition, we did not look at the rate of metabolism and elimination of the tested cytokines and enzyme, and therefore we could not prove that the high serum troponin level is attributable to cardiac injury alone. Although a reduced metabolic rate, such as that occurring during hypothermia, should decrease the production of both the cytokines and troponin, the serum levels of these compounds were higher during low, but not high, body temperatures, indicating the presence of cardiac damage. We did not conduct cost-effective analyses of the thermo-wrap garment, but it is reasonable to assume that any acceleration of recovery time and earlier discharge from the ICCU will produce economic benefits. Finally, data on patients who underwent thoracostomy would have been especially relevant to the current study, but this procedure is not performed in any of the 3 participating centers.

In conclusion, normalization of the two physiologically balanced pathways of inflammatory and anti-inflammatory responses after OBCAB surgery was in part caused by normothermia. Although group differences in IL-8 and IL-10 did not reach the level of statistical significance, we speculate that they might have done so and that they would have had a more pronounced clinical effect in a larger cohort, thereby further enhancing patient outcome after $\mathrm{OPCAB}$ and possibly other heart operations.

We thank Esther Eshkol, MA, institutional medical and scientific copyeditor, Tel Aviv Sourasky Medical Center, for editorial assistance.

\section{References}

1. Menasche P, Peynet J, Haeffner-Cavaillon N, Carreno MP, de Chaumaray $\mathrm{T}$, Dillisse V, et al. Influence of temperature on neutrophil trafficking during clinical cardiopulmonary bypass. Circulation. 1995; 92(suppl II):II334-40.

2. Insler SR, O'Connor MS, Leventhal MJ, Nelson DR, Starr NJ. Association between postoperative hypothermia and adverse outcome after coronary bypass surgery. Ann Thorac Surg. 2000;70:175-81.
3. Matsukawa T, Kurz A, Sessler DI, Bjorksten AR, Merrifield B, Cheng C. Propofol linearly reduces the vasoconstriction and shivering thresholds. Anesthesiology. 1995;82:1169-80.

4. Matsukawa T, Sessler DI, Sessler AM, Schroeder M, Ozaki M, Kurz A, et al. Heat flow and distribution during induction of general anesthesia. Anesthesiology. 1995;82:662-73.

5. Angele MK, Faist E. Clinical review: immunodepression in the surgical patients and increase susceptibility to infection. Crit Care. 2002; 6:298-305.

6. Nesher N, Zisman E, Wolf T, Sharony R, Bolotin G, David M, et al. Strict thermoregulation attenuates myocardial injury during coronary artery bypass graft surgery as reflected by reduced levels of cardiacspecific troponin I. Anesth Analg. 2003;96:328-35.

7. Kirklin JK, Westaby S, Blackstone EH, Kirklin JW, Chenoweth DE, Pacifico AD. Complement and the damaging effects of cardiopulmonary bypass. J Thorac Cardiovasc Surg. 1983;86:845-57

8. Utley JR. The immune response and cardiopulmonary bypass. In: Gravlee GP, Davis RF, Utley JR, editors. Principles and practice of cardiopulmonary bypass. Baltimore: Williams \& Wilkins; 1993. p. 249-66.

9. Wan S, LeClerc JL, Vincent JL. Cytokine responses to cardiopulmonary bypass: lessons learned from cardiac transplantation. Ann Thorac Surg. 1997;63:269-76.

10. Fong Y, Moldawer LL, Shims GT, Lowry SF. The biologic characteristics of cytokines and other implications in surgical injury. Surg Gynecol Obstet. 1990;170:363-78.

11. Hayashida N, Ikonomidis JS, Weisel RD, Shirai T, Ivanov J, Carson SM, et al. The optimal cardioplegic temperature. Ann Thorac Surg. 1994;58:961-71.

12. Hennein HA, Ebba H, Rodriguez JL, Merrick SH, Keith FM, Bronstein $\mathrm{MH}$, et al. Relationship of the proinflammatory cytokines to myocardial ischemia and dysfunction after uncomplicated coronary revascularization. J Thorac Cardiovasc Surg. 1994;108:626-35.

13. Struber M, Cremer JT, Gohrbandt B, Hagl C, Jankowski M, Volker B, et al. Human cytokine responses to coronary artery bypass grafting with and without cardiopulmonary bypass. Ann Thorac Surg. 1999; 68:1330-5

14. Diegeler A, Doll N, Rauch T, Haberer D, Walther T, Falk V, et al. Humoral immune response during coronary artery bypass grafting. Circulation. 2000;102(suppl III):III95-100.

15. Howard R. Effect of burn injury, mechanical trauma, and operation on the immune defense. Surg Clin North Am. 1980;59:199-207.

16. Bonnefoy E, Filley S, Kirkorian G, Guidollet J, Roriz R, Robin J, et al. Troponin I, troponin T, or creatine kinase-MB to detect perioperative myocardial damage after coronary artery bypass surgery. Chest. 1998; $114: 482-6$

17. Ikeda U, Ikeda M, Oohara T, Oguchi A, Kamitani T, Tsuruya Y, et al. IL-6 stimulates growth of vascular smooth muscle cells in a PDGFdependent manner. Am J Physiol. 1991;260:H1713-7.

18. Funakoshi Y, Ichiki T, Ito K, Takeshita A. Induction of IL-6 expression by angiotensin II in rat vascular smooth muscle cells. Hypertension. 1999;34:118-25.

19. Browatzki M, Schmidt J, Kubler W, Kranzhofer R. Endothelin-1 induces IL-6 via activation of the transcription factor NF-kappaB in human vascular smooth muscle. Basic Res Cardiol. 2000;95:98-105.

20. Ito T, Ikeda U, Shimpo M, Yamamoto K, Shimada K. Serotonin increases IL-6 synthesis in human vascular smooth muscle cells. Circulation. 2000;102:2522-7.

21. Burger A, Benicke M, Deten A, Zimmer HG. Catecholamines stimulate IL-6 synthesis in rat cardiac fibroblast. Am J Physiol. 2001;281: H14-21.

22. Puskas JD, Williams WH, Duke PG, Staples JR, Glas KE, Marshall JJ, et al. Off-pump coronary artery bypass grafting provides complete revascularization with reduced myocardial injury, transfusion requirements, and length of stay: prospective randomized comparison of two hundred unselected patients undergoing off-pump versus conventional coronary artery bypass grafting. J Thorac Cardiovasc Surg. 2004;125: 797-808.

23. Mack M, Bachand D, Acuff T, Edgerton J, Prince S, Dewey T, et al. Improved outcome in coronary artery bypass grafting with beatingheart techniques. J Thorac Cardiovasc Surg. 2002;124:598-607. 